Revista aSEPHallus de Orientação Lacaniana

Núcleo Sephora de Pesquisa sobre o Moderno e o Contemporâneo

ISSN 1809 - $709 \mathrm{X}$

\title{
Transmissão em psicanálise
}

\author{
Marcia Infante Vieira \\ Orcid: https://orcid.org/0000.0002-0325-6998 \\ Doutoranda do Programa de Pós-Graduação em Teoria Psicanalítica/UFRJ (Rio de Janeiro, Brasil) \\ Mestrado no Programa de Pós-Graduação em Teoria Psicanalítica/ UFRJ (Rio de Janeiro, Brasil) \\ Membro do Instituto Sephora de Ensino e Pesquisa de Orientação Lacaniana/ ISEPOL (Rio de Janeiro, Brasil) \\ Psicóloga/ PUC (Rio de Janeiro, Brasil) \\ E-mail: marcia.infante.vieira1957@gmail
}

Resumo: Nesse artigo, pretendo responder à questão que ocupa a mídia atualmente, quanto ao caráter conservador ou revolucionário da psicanálise. Tendo em vista que nos círculos feministas radicais Freud é criticado como misógino, tomei como ponto de partida um recuo histórico na teoria freudiana enfocando os efeitos psíquicos da distinção anatômica entre os sexos. 0 eixo orientador desse trabalho é a hipótese de que é impossível levar essa questão adiante sem articular a prática da psicanálise com a sua transmissão.

Palavras-chave: psicanálise; transmissão; castração; significante.

Transmission en Psychanalyse: Dans cet article, je cherche a répondre à la question, qui ocupe les médias de nos jour, concernant le caractère conservateur ou révolutionnaire de la psychanalyse. Compte tenu du fait que dans les cercles féministes radicaux, Freud est vu comme un misogyne, jai pris come point de depart un retrait historique de la théorie freidienne centrée sur les effets psychiques de la distinction anatomique entre les sexes. L'axe directeur de ce travail est I'hypothèse selon laquelle il est impossible de faire avancer cette question sans articuler la pratique de la psychanalyse avec sa transmission.

Mot-clés: psychanalyse; transmission; castration; signifiant.

Transmission in psychoanalysis: In this article I intend to answer the question that is currently in the media, regarding the conservative or revolutionary character of psychoanalysys. Given that in radical feminist circles Freud is read as a mysoginist, I take as a starting point a historical retreat in freudian theory focusing on the effects of the anatomical distinction between the sexes. The axis of this work is the hypothesis that it is impossible to take this issue forward without articulating the practice of psychoanalysis with its transmission.

Keywords: psychoanalysis; transmission; castration; significant. 
Revista aSEPHallus de Orientação Lacaniana

Núcleo Sephora de Pesquisa sobre o Moderno e o Contemporâneo

ISSN $1809-709$ X

\section{Transmissão em psicanálise ${ }^{1}$}

Márcia Infante Vieira

\section{Introdução}

A teoria freudiana sobre os efeitos psíquicos da distinção anatômica entre os sexos requer um recuo histórico para situá-la no debate acerca do conservadorismo ou do vanguardismo da psicanálise. Esse debate, atualmente, vem ocupando um lugar de destaque na mídia, onde grupos radicais do movimento feminista acusam Freud de ter sido um misógino e, desta feita, alegam que a psicanalise é uma prática reacionária. Acreditando ser impossível levar essa questão adiante sem articular a prática da psicanalise com a sua transmissão, tomei como ponto de partida o livro de Clotilde Leguil (2016), O ser e o gênero: homem/mulher depois de Lacan. O ponto de vista desta autora se sustenta na seguinte postulação: "Para a psicanálise, o que está em jogo não é meramente uma identificação imaginária a um gênero ou outro, mas a posição de objeto que cada um foi para o Outro e o destino dado a isso na fantasia inconsciente que irá propiciar a identificação sexual e a escolha de objeto para cada um" (Leguil, 2016, p. 11).

Sua posição se coaduna com o lugar dado ao Outro por Lacan (1955-1956/1985), que é o de estar no início de todo o processo de construção da subjetividade do ser a advir, marcando-o com inscrições que se dão no nível da carne. Para Leguil, nessas inscrições o que se transmite são significantes oriundos dos desejos, fantasias e sexualidade dos pais. Por este motivo, tal discussão ocorre no campo psíquico, que vem funcionar como um solo onde significantes transgeracionais operam.

\section{Romances familiares}

Em 1909, Freud publicou Romances Familiares, artigo no qual plantou a semente do que posteriormente Lacan (1938/2003) veio a trabalhar em seu artigo intitulado Complexos Familiares. $\mathrm{O}$ que Freud evidenciou nesse estudo foi o papel desempenhado pelas figuras parentais no desenvolvimento da estrutura psíquica de cada criança. Sua pesquisa, segundo Roudinesco (2016), parte da observação de sua própria construção fantasística em relação à sua vida familiar. Freud foi filho das segundas núpcias de seu pai Jacob. Sua mãe, Amalia, era muito mais nova do que o marido. Dessa feita, o meio irmão de Freud, chamado Philipp, tinha uma idade que se aproximava da idade de Amalia. Freud emprestou sua imaginação à essa cena familiar e construiu um romance entre Amalia e seu meio irmão, do qual ele seria filho. A paternidade de Jacob foi então negada.

Esta capacidade de devanear - que Freud anteriormente acreditava ser um mecanismo exclusivo da paranoia - se tornou parte fundamental do desenvolvimento psíquico de toda criança. Freud nomeou tal devaneio de "Romance Familiar", romance oriundo da necessidade da criança de alcançar autonomia em relação aos pais, que até esse momento eram percebidos como perfeitos. $\mathrm{Na}$ ânsia por independência ela começa a desconstruir essas imagens idealizadas, comparando 
seus pais a outras realidades familiares geralmente mais abastadas. Essa desconstrução alcançou o benefício da dúvida, que veio colocar a paternidade em xeque.

Freud identificou um outro fator responsável pela desidealização dos pais: as consequências da chegada de um irmão no seio familiar. Como efeito, ele reconheceu a fantasia de ser filho adotivo como uma fantasia universal. O enredo também foi cartografado por momentos de oscilações entre a real paternidade biológica e a identificação com a figura do pai herói, na paternidade, e por oscilações entre a que representa o objeto de amor e a que encarna a figura da traidora, na maternidade. Vale ressaltar que esses romances foram definidos por Freud tendo como tema central o complexo de Édipo.

Um ano depois, em 1910, Freud retomou este tema no artigo intitulado Um tipo especial de escolha de objeto feita pelos homens (Contribuições à psicologia do amor I). Ali ele abordou as pré-condições necessárias para o amor que determinavam os tipos de escolha de objeto eleitos pelos homens. Freud reconheceu como primeira condição aquela em que a mulher eleita configura, junto ao homem, uma situação triangular. Para que esta fantasia se realize é necessário que ela esteja comprometida com outro homem, pois a existência de uma pessoa prejudicada, um noivo ou um marido que possa reivindicar o direito de posse sobre ela, funciona como gatilho para que esse homem se apaixone. Freud destacou que essa pré-condição fornece a oportunidade de gratificação de impulsos de rivalidade e hostilidade contra o homem do qual a mulher é arrebatada.

A segunda pré-condição foi nomeada por Freud como "amor à prostituta". Ele a conjugou com a primeira pré-condição e ressaltou que a mulher casta, nesses casos, não conseguiria exercer atração que a conduzisse ao posto de objeto amoroso. Nessa cartografia, as mulheres eleitas pelos homens seriam aquelas reconhecidas como as de má reputação sexual, difamadas e de caráter duvidoso. Freud distinguiu nesse enredo a existência do ciúme e acreditou ser preciso que esse sentimento alcançasse $o$ ápice para que o homem pudesse se apaixonar. Ele ressaltou também que, em ambos os casos, esses homens se sentiriam confortáveis em uma situação triangular. A investigação clínica lhe revelou o caráter de natureza compulsiva presente nesses comportamentos amorosos. Portanto, os objetos amorosos poderiam se substituir formando uma extensa série.

Freud identificou ainda uma terceira característica desses amantes: a ânsia de salvar a mulher amada. Ele pôde observar que, nesse enredo, o homem se encontrava convencido de que essa mulher dependeria dele moralmente e, por conta disso, ele lhe emprestava suas virtudes.

Após discriminar essas pré-condições, Freud afirmou que essa maneira singular de se comportar no amor tem a mesma origem psíquica da forma de amar das pessoas normais. Ele localizou essa fonte comum na fixação infantil dos sentimentos de ternura pela mãe, fixação ocasionada pelo longo tempo em que a criança teria permanecido nessa ligação, o que viria a imprimir nos outros objetos amorosos, eleitos ao longo da vida, as mesmas características dessa ligação primordial. 
Portanto, Freud ancorou na constelação psíquica relacionada à mãe tanto as condições para amar quanto o comportamento amoroso do homem. Nesse circuito familiar, o pai foi definido como o outro que se interpõe em relação à amada, ou seja, aquela pessoa injuriada presente na cena da primeira pré-condição amorosa. Contudo, Freud alegou que a superestimação da figura materna seria decorrente do fato de a mãe ser única e insubstituível.

Freud relacionou a segunda pré-condição, a do amor pela mulher de baixa reputação, às pesquisas sexuais infantis nas quais o menino percebe que seus pais se relacionam sexualmente. Como efeito desta descoberta, a criança nega a atividade sexual da mãe e a cinde em seu psiquismo entre a representação da mulher casta e a representação daquela que vive o sexo livremente. No entanto, essa negação não se sustenta por muito tempo, pois a criança vai alcançando graus cada vez maiores de entendimento sobre a vida sexual dos adultos. Como um desdobramento desse processo de crescimento, Freud reconheceu o desejo do menino pela mãe seu primeiro objeto amoroso - como o enredo edípico em que a criança se encontra mergulhada, vivendo suas fantasias eróticas, que se soma à prática da masturbação na puberdade. Nessa aliança Freud localizou o que vem a ser o futuro solo de onde brota a escolha da prostituta como objeto amoroso.

Na pré-condição de "salvamento", Freud reconheceu que o menino também estaria inserido no complexo parental. Dessa feita, por se sentir grato pela mãe que the deu a vida, ele deseja Ihe retribuir com outra vida: um filho igual a ele mesmo. Para obter êxito no desfecho dessa fantasia de salvamento o menino precisa se identificar com o pai, para que, tomado de ternura, gratidão e independência, alcance o desejo de ser igual a ele.

Freud concluiu esse artigo afirmando que esse sujeito chegou ao mundo inserido na fantasia oriunda de uma configuração familiar onde vetores operaram determinando a necessidade de um salvador. Ele entrou nessa fantasia em posição de objeto, não Ihe restando alternativas a não ser se deixar adorar. Freud advertiu que poderia parecer que toda a estrutura dependesse da criança, mas, na verdade, ela foi apenas uma serva dessa constelação familiar.

Em suma, Freud constatou que as modalidades do amor dependem de que o objeto de desejo preencha algumas condições que se encontram ancoradas no complexo de Édipo, com seu rochedo intransponível que é a castração. Os sujeitos humanos, quer sejam homens ou mulheres, têm que se haver com esse obstáculo que aponta para a realidade de serem sujeitos faltosos, incompletos e marcados desde a origem pela existência do Outro. Esse Outro fura a ilusão de unidade do indivíduo na medida em que, através da linguagem, o ser, desde sua mais tenra infância, é afetado pela civilização.

O humano nasce precoce, pois imaturo em relação às capacidades de sobreviver sem um Outro suficientemente capacitado que venha dar conta de suas necessidades básicas. Da necessidade cria-se a demanda, que por se encontrar impossibilitada de ser respondida em sua totalidade cria o desejo. 
Ao acompanhar as ideias sobre a psicologia da vida amorosa pode-se concluir que a falta é estrutural, sendo essa, no entanto, a castração original. Na vida psíquica a castração recai sobre a diferença sexual, ou seja, no inconsciente a castração se representa pelo que um sexo difere do outro. E é nesse ponto que os romances familiares se inserem, dando um tratamento ao oco, ao vazio que se configura a partir da constatação da "não-relação sexual" (Lacan, 1972-1973/2008).

\section{Complexos familiares}

Visando dar um passo a mais na fundamentação teórica desse estudo sob à luz da psicanálise, lançarei mão do artigo de Jacques Lacan, de 1938, Complexos familiares na formação do indivíduo. Nesse artigo o autor, seguindo os passos de Freud, reconhece três complexos básicos e universais que são transmitidos pela família: o desmame, a intrusão do terceiro e as relações entre os objetos parentais.

A família afigura-se, a princípio, um grupo natural de indivíduos unidos por uma dupla relação biológica: a geração que fornece os componentes do grupo; as condições do meio postuladas pelo desenvolvimento dos jovens e que mantém o grupo, desde que os adultos geradores assegurem sua função. (Lacan, 1938/2003, p. 29).

Freud (1930/1976) já advertira que a cultura é resultante de um pacto entre os seres humanos e tem como propósito a renúncia da parcialidade das pulsões em nome de uma vida comunitária onde a espécie humana pudesse somar suas forças individuais contra as adversidades da natureza e contra a lei do mais forte. Lacan (1938/2003) caminhou alinhado com as ideias freudianas e concluiu que essa obra coletiva se evidencia nos fenômenos sociais do homem, inclusive na família. Acreditou que, apesar de o ser humano ter um funcionamento biológico, as instâncias culturais o dominam. Considerou que as estruturas hierárquicas da família, bem como os laços construídos em seu interior denunciam sua formação moral. Afirmou que a família é uma instituição de estrutura complexa, já que:

[...] os modos de organização dessa autoridade familiar, as leis de sua transmissão, os conceitos de descendência e parentesco que the estão ligados, as leis da herança e da sucessão que com ela se combinam, enfim, suas relações íntimas com as leis do casamento - obscurecem as relações psicológicas, embaralhando-as. (Lacan, 1938/2003, p. 30).

Para Lacan, toda essa configuração coloca a família na linha de frente em relação às outras instituições transmissoras da cultura. Essa transmissão se dá em um nível para além da consciência, o que garante uma continuidade entre as gerações, tendo como elo a organização 
mental. A seu ver, família e casamento, apesar de serem instituições distintas, entrelaçam-se, demarcando a influência que a segunda exerce sobre a primeira.

Lacan (1938/2003) estudou profundamente os complexos e de que forma, diferentemente dos instintos, eles desempenhariam o papel de organizadores no desenvolvimento psíquico das famílias. O primeiro a ser estudado foi o complexo do desmame, relacionado no psiquismo à amamentação. Para o autor, esse complexo é o mais primitivo e não se dissolveria com o aparecimento dos complexos posteriores e, sim, os comporia. Lacan ressaltou a dominância que os fatores culturais exercem sobre ele desde a origem, já que, no homem, diferentemente do que ocorre nos animais, o desmame é condicionado por uma regulação cultural.

O desmame, segundo Lacan, pode ser psiquicamente traumático e gerar efeitos - como os transtornos alimentares, as drogadicções e as doenças gástricas -, sintomas evidenciados na clínica psicanalítica. Mesmo não havendo trauma, a marca da interrupção se inscreve e demanda trabalho ao psiquismo. "Pela primeira vez, ao que parece, uma tensão vital resolve-se numa intenção mental. Através dessa intenção, o desmame é aceito ou recusado" (Lacan, 1938/2003, p. 37).

A recusa do desmame instala o ponto do complexo que visa restabelecer a imago perdida. $\mathrm{O}$ eu ainda imaturo, porque precoce em seu desenvolvimento, não representa essa experiência tornando-a consciente; tudo se passa ao nível das sensações, que se inscrevem no aparelho moldando as experiências psíquicas posteriores.

Todo esse mecanismo expressa o quanto a criança, em sua mais tenra idade, parece reconhecer como um fato estrutural a presença da função materna. A reboque desse romance, sentimentos ambivalentes são experimentados como mal-estar, o que tem como causa "[...] uma adaptação insuficiente à ruptura das condições ambientais e de alimentação que compõe o equilíbrio parasitário da vida intra-uterina" (Lacan, 1938/2003, p. 41). No entanto, Lacan não localizou no momento do nascimento a sede do trauma psíquico. Acreditou que seria a prematuridade biológica do bebê humano que o colocaria num estado de desamparo, o qual nenhum cuidado materno seria capaz de suprir. "Assim constituída, a imago do seio materno domina a vida do homem" (Lacan, 1938/2003, p. 41). Portanto, desamparo, mas não abandono, uma vez que o abraço materno, repleto de satisfação, compensa a criança do afeto de angústia primeiro dos fenômenos afetivos a surgir.

Sublimar essa imago é a saída da criança tanto para a socialização, quanto para que novos complexos passem a integrar o psiquismo. Caso contrário, segundo Lacan, esse fato transforma-se em um fator de morte. No entanto, mesmo havendo sublimação, a imago do seio materno não se dissolve por completo e a cada nova investida do eu o desmame se reedita.

O outro complexo abordado por Lacan (1938/2003) é o complexo de intrusão, que ocorre quando o sujeito se reconhece entre irmãos. Esse reconhecimento está intimamente ligado ao lugar conferido ao sujeito na ordem de nascimento da família. Para Lacan, antes de qualquer 
conflito, o sujeito ocupa nesta dinastia o lugar de abastado ou o de usurpador. Disso decorre que o sentimento de ciúmes entre irmãos antecede à rivalidade, representando uma identificação mental.

O confronto de rivais, para o autor, já se evidencia em crianças de 2 e 3 anos, sendo as reações mais frequentes as "[...] de exibição, de sedução e do despotismo" (Lacan, 1938/2003, p. 44). São essas três estruturas que, de forma bipolar, habitam cada um dos pequenos sujeitos em jogo nessa cena. Em uma coreografia de identificação e indiscriminação com o outro, os protagonistas têm como saldo uma imago relacionada "[...] à estrutura do próprio corpo e, mais especialmente, de suas funções de relação, por uma similitude objetiva" (Lacan, 1938/2003, p. 44).

A psicanálise aponta uma basculação na relação entre irmãos por duas vias afetivas: o amor e a identificação. Lacan reconheceu que o ciúme que surge na situação fraterna está ligado à amamentação. Nesse momento, a agressividade seria secundária à identificação. Apesar de a fase sadomasoquista da libido aparecer como tendência nesse período do desenvolvimento psíquico, ela está sustentada "[...] por uma identificação com o outro que é o objeto da violência" (Lacan, 1938/2003, p. 45). Em outras palavras, a ocorrência desse fenômeno está atrelada a certa identificação com o estado do irmão, que permite o sujeito consumar-se.

Lacan (1938/2003) denominou essa identificação como estágio do espelho, fase genética do desenvolvimento psíquico que estrutura a realidade do sujeito a partir dos 6 meses de vida. Sua imagem especular refletirá sua forma humana. "A percepção da forma do semelhante como unidade mental está ligada no ser vivo a um nível correlativo de inteligência e sociabilidade" (Lacan, 1938/2003, p. 47). Esse fenômeno perceptivo é uma tentativa de organização de partes despedaçadas do corpo, correlativas às pulsões parciais. Ele reconheceu a consciência tendo em seu centro a tendência de restabelecer a própria unidade perdida do sujeito. Dessa feita, seu percurso mental seria marcado pela visão e estruturado pela sua imagem especular. Portanto, essa imagem vem conferir ao sujeito sua unidade mental e, concomitantemente, o reconhecimento do ideal da imago do duplo.

Portanto, nesse momento do desenvolvimento, o bebê se encontra inserido num mundo narcísico onde o outro ainda não existe. $O$ outro é ativo em todo esse processo, mas não de forma suficiente para romper com esse isolamento afetivo. 0 outro é percebido como um estrangeiro, isto é, como uma intrusão narcísica responsável pela formação do eu. O eu e o outro se confundem; logo, primordialmente, o eu se encontra alienado.

Retornando à questão do ciúme, podemos ver como esse sentimento é constituinte do destino do sujeito em direção à sua socialização. Com a entrada de um objeto terceiro, inaugurase uma situação triangular que possibilita a saída do sujeito dessa alienação primordial. O ciúme, nesse sentido, "[...] revela-se o arquétipo dos sentimentos sociais" (Lacan, 1938/2003, p. 50). Por um lado a intrusão, e, por outro, como modelo arcaico do eu, o complexo fraterno inscreve seus 
traços psíquicos; momento em que, através do semelhante, tanto o objeto quanto o eu se inscrevem.

O terceiro complexo abordado por Lacan é o complexo de Édipo, ponto de partida da clínica das neuroses através do qual Freud inaugurou o conceito de complexo. Lacan fez uma releitura partindo do fato de que:

Freud aponta esse elemento psicológico como sendo a forma específica da família humana e Ihe subordina todas as variações sociais da família. A ordem metódica aqui proposta, na consideração tanto das estruturas mentais quanto das realidades sociais, conduzirá a uma revisão do complexo que permitirá situar na história a família patriarcal e esclarecer melhor a neurose contemporânea. (Lacan, 1938/2003, p. 52).

Lacan seguiu os passos freudianos ao afirmar que o complexo forma-se pela frustração das pulsões sexuais da criança em torno dos 4 anos de idade que, geralmente, se dirige para o genitor do mesmo sexo que vem funcionar como obstáculo desta satisfação. Desta feita, ele também acreditou que a repressão educacional teria um papel relevante, interditando a realização dessas pulsões sexuais. No entanto, a criança percebe tanto o proibido quanto os aspectos difusos das relações parentais. Como efeito dessa percepção, o genitor do mesmo sexo se configura numa dupla vertente, ou seja, como agente da interdição sexual e, concomitantemente, como exemplo de sua transgressão. A resultante desse processo é o recalcamento da tendência sexual que, por entrar em estado de latência, vem a ser substituída por interesses educacionais até seu reaparecimento na puberdade.

O destino da imagem parental foi indicado por Lacan como sendo o da sublimação. Tal imagem permanece na consciência como um ideal representativo e regulará, no futuro, o funcionamento psíquico. Desta feita, ele descreveu duas instâncias no psiquismo: o supereu, que recalca; e o ideal do eu, que sublima.

Descobrir que desdobramentos tão importantes para o ser humano como são os da repressão sexual e do sexo psíquico estavam sujeitos à regulação e aos acidentes de um drama psíquico da família era fornecer a mais preciosa contribuição para a antropologia do grupo familiar, especialmente para o estudo das proibições que esse grupo formula universalmente, e que tem por objeto o comércio sexual entre alguns de seus membros. Por isso mesmo, Freud veio rapidamente a formular uma teoria da família. Ela se baseou numa dissimetria, surgida desde as primeiras investigações, na situação dos dois sexos em relação ao Édipo. (Lacan, 1938/2003, p. 54) 
Para a psicanálise, o complexo de Édipo marca todos os níveis do psiquismo a partir de um amadurecimento progressivo da sexualidade que visa atingir uma organização genital. Na direção tendente ao objeto, o complexo opera por um conflito triangular que impõe uma mudança na tendência dos investimentos nos objetos primitivos. Lacan acreditou que esse ponto possibilita um equívoco entre o que é da ordem de uma provação vital e o que é da ordem de uma provação moral. Ele respondeu a essa questão alegando que o complexo de Édipo se constitui em uma dupla vertente: ele é tanto um processo de interdição quanto de sublimação e seus veículos são o supereu e o ideal do eu, que reproduzem a imago paterna em consonância com uma dominação masculina.

Ao afirmar que a fantasia de castração é o sustentáculo da repressão da sexualidade, Lacan discorreu sobre a prematuração do corpo biológico do infans: "A fantasia de castração é percebida, com efeito, por toda uma série de fantasias de despedaçamento do corpo, que regridem da desarticulação e do desmembramento, passando pela evisceração, pelo desventramento, até a devoração e o sepultamento" (Lacan, 1938/2003, p. 58). Com essa argumentação, Lacan deslocou o tempo da fantasia de castração para um momento anterior a qualquer delimitação de um corpo próprio, anterior a qualquer possibilidade de intervenção ameaçadora por parte de um adulto e independente do sexo do sujeito. Nesse deslocamento temporal, a fantasia teria um papel mais determinante do que determinada pela tradição educacional. Sua função seria defensiva, estando a serviço do eu narcísico, diante do abalo proveniente da angústia deflagrada no primeiro momento do Édipo, ou seja, o desmame, a separação da mãe. Lacan concluiu que "[...] para definir no plano psicológico essa gênese da repressão, devemos reconhecer na fantasia de castração o jogo imaginário que a condiciona, e na mãe, o objeto que a determina" (Lacan, 1938/2003, p. 59).

Segundo Lacan, apesar de o supereu já ter recebido traços da realidade pela repressão materna, no momento do desmame e do controle dos esfíncteres, é somente na fase genital do complexo de Édipo que há o atravessamento da sua forma narcísica. Nessa passagem, inaugura-se a sublimação da realidade via identificação, forma concebida com a resolução do drama edípico, onde a imago do genitor do mesmo sexo é internalizada, tendo como verificador dessa imago o supereu e o ideal do eu. Essa identificação é considerada como um segundo momento do narcisismo, ou conceituada como narcisismo secundário. Ainda nessa fase há indiferenciação entre o eu e o outro. $\mathrm{O}$ eu encontra-se assimilado ao objeto e, a imago com a finalidade de impor-se ao sujeito, justapõe-se ao eu.

Lacan engendrou originalidade no conceito de identificação edipiana quando reconheceu que "[...] no complexo de Édipo, não é o momento do desejo que erige o objeto em sua nova realidade, mas sim o da defesa narcísica do sujeito" (Lacan, 1938/2003, p. 61). Essa posição desvelou que o objeto do desejo é o que faz oposição no triangulo edipiano, entendimento que apontou para uma ameaça relacionada à transgressão. No eu, ele é sentido como defesa e triunfo, 
preenchendo o lugar do duplo com quem, inicialmente, o eu se identificou. Esse processo de revestimento do objeto fornece o protótipo da sublimação, designado pelo pai na estrutura edipiana. Em relação à imago materna, a herança que a identificação carrega é a das identificações primordiais.

Lacan ressaltou que apesar da análise psicológica do Édipo ser compreendida a partir dos antecedentes narcísicos, isso não exclui que ele esteja fundido na realidade do laço social. Ele entendeu que a força dos efeitos psíquicos da função do pai, tanto a repressão quanto a sublimação, são determinadas socialmente pela família patriarcal. Portanto, o complexo de Édipo está absolutamente relacionado à estrutura social vigente. A seu ver, a força que a imago paterna é investida provém de um patrimônio cultural que abarca ideais normativos, estatutos jurídicos e inspirações criadoras. E afirmou que do individual ao coletivo "[...] o conflito funcional do Édipo, reintegra no processo psicológico a dialética social gerada por esse conflito" (Lacan, 1938/2003, p. 63).

Lacan insistiu na ideia de que a tradição histórica patriarcal ofuscou a força do matriarcado subjacente em toda cultura antiga. Pautado em estudos sociológicos das culturas primitivas, datados de épocas anteriores ao nascimento da humanidade, o autor verificou que os mitos evidenciavam a emancipação das tiranias matriarcais. Desta feita, ele levantou a hipótese de que o ideal patriarcal teria surgido contra a sedução sem freio das mulheres dessas culturas. Dialeticamente, constatou que o ideal patriarcal se universalizou e produziu na sociedade uma exigência para os indivíduos. A família, em sua estrutura, foi afetada por esses ideais legitimados através dos laços de casamento e da religião.

Diante dessa avaliação, Lacan discriminou o objeto de estudo dos psicanalistas: os laços do sujeito moderno com a família conjugal. Para que a família conjugal se realize é preciso que existam três condições, todas elas atreladas à autoridade paterna: a primeira evidencia a instalação da ordem geracional, uma vez que ela atinge um alcance subversivo criador; a segunda relaciona-se ao caráter transmitido pelo ideal do eu; a terceira diz respeito à vida sexual que se expressa através da tensão da libido e da importância da sublimação.

E por materializar da maneira mais humana o conflito do homem com sua angústia mais arcaica, é por the oferecer o mais leal campo fechado em que ele pode bater-se com as figuras mais profundas de seu destino, é por colocar ao alcance de sua existência individual a vitória mais completa sobre sua servidão original, que o complexo da família conjugal cria os sucessos superiores de caráter, da felicidade e da criação. (Lacan, 1938/2003, p. 66).

É no período de latência, a partir dos confrontos sociais dessa fase, que o racional do indivíduo se forma com maior eficiência. Essa formação racional está intimamente ligada à 
experiência familiar devido às diversificações provenientes das realidades inconscientes internalizadas. Esse fato atesta que o que é experimentado no seio dos laços familiares ultrapassa qualquer prática pedagógica.

A modernidade produziu afrouxamentos nos laços sociais que se desdobraram em um declínio da imago paterna. Essa crise psicológica propiciou o surgimento da psicanálise, uma vez que Freud identificou nos sintomas neuróticos uma relação de dependência com as condições familiares da sua época.

Essas neuroses, desde o tempo das primeiras adivinhações freudianas, pareciam ter evoluído no sentido de um complexo caracterológico no qual, tanto pela especificidade de sua forma quanto por sua generalização - ele é o núcleo da maioria das neuroses podemos reconhecer a grande neurose contemporânea. Nossa experiência leva-nos a apontar sua determinação principal na personalidade do pai, sempre de algum modo carente, ausente, humilhada, dividida ou postiça. É essa carência que, de acordo com nossa concepção do Édipo, vem estancar tanto o ímpeto instintivo quanto a dialética das sublimações. Qual madrinhas sinistras instaladas no berço do neurótico, a impotência e a utopia aprisionam sua ambição, seja porque ela sufoca em si as crianças esperadas pelo mundo em que nasce, seja porque, no objeto que propõe para sua revolta, ele desconhece seu próprio movimento. (Lacan, 1938/2003, p. 67)

Freud identificou a origem dos sintomas ancorada pela fantasia, ou pela realidade de um abuso sexual sofrido pela criança por parte de um adulto, de onde se desdobraria o trauma. Apesar dessa noção de trauma implicar o risco de uma desordem na vida sexual futura, ela também insere a noção de estrutura, ou seja, a tendência desses complexos formarem a organização normal da família a partir dos primeiros objetos a serem investidos.

[...] nenhum fato precipita mais essa formação do que o nascimento de um irmão, que exalta, por seu enigma, a curiosidade da criança, reativando as emoções primordiais de seu apego à mãe, pelos sinais de sua gravidez e pelo espetáculo dos cuidados que ela presta ao recém-nascido, e por fim cristalizando, na presença do pai junto dela, o que a criança advinha do mistério da sexualidade, o que ela sente por seus impulsos precoces e o que teme pelas ameaças que Ihe proíbem sua satisfação masturbatória. Tal é, pelo menos definida por seu grupo e por seu momento, a constelação familiar que para Freud forma o complexo nodal das neuroses. Ele extraiu daí o complexo de Édipo. (Lacan, 1938/2003, p. 76) 
O sintoma do neurótico denuncia sua divisão, na medida em que esse sujeito não se reconhece naquilo que the causa sofrimento. Freud descobriu que através da análise do sintoma o sujeito, gradativamente, apropriava-se do conhecimento de si e fazia com que as manifestações sintomáticas se diluíssem. O eixo consciência da origem, dando a direção da cura, acenou como promissora, até que um fenômeno nomeado como resistência se impôs e dificultou essa elucidação. A compreensão do processo de formação do sintoma redirecionou-se do viés da revelação do inconsciente para o viés da defesa contra a angústia. Freud reconheceu nessa angústia o sinal da separação primordial, que seria reeditada diante da ameaça de castração. Desta feita, o sintoma passou a ser identificado como uma defesa do sujeito diante da realidade, que se construiu através da via simbólica ou pela via da sublimação. Lacan acreditou que essa nova visão da função do sintoma passou a ser considerada estrutural, e o nascimento foi reconhecido como o momento da separação primordial.

Com efeito, é a partir de uma identificação com seu semelhante que, através da participação ciosa e da ocorrência simpática, o eu se diferencia, num progresso comum, do outro e do objeto. A realidade inaugurada por esse jogo dialético preserva a deformação estrutural do drama existencial que a condiciona e que podemos chamar de drama do indivíduo, com ênfase que esse termo recebe da prematuração da espécie. [...] Mas essa estrutura só se diferencia plenamente ali onde reconhecemos de início, no conflito da sexualidade infantil, o que é concebível pelo fato de que só então ela cumpre sua função quanto à espécie: assegurar a correção psíquica da prematuração sexual - o supereu pelo recalque do objeto biologicamente inadequado que é proposto ao desejo, por sua maturação primária, e o ideal do eu pela identificação imaginária que orientará a escolha para o objeto biologicamente adequado na maturação puberal. (Lacan, 1938/2003, p. 7879).

A partir de uma nostalgia da mãe, o sujeito ruma para a idade da razão, alcançando autonomia e se inserindo afetivamente na realidade através da integração da sexualidade. A família foi identificada, tanto por Freud quanto por Lacan, como tendo um papel fundamental na origem das neuroses. Este papel revela os efeitos do complexo de Édipo, tanto no que diz respeito à estruturação do eu quanto às imagos que ela introduz.

A regulação desses efeitos concentra-se no complexo, à medida que se racionalizam as formas de comunhão em nossa cultura, numa racionalização que ele determina reciprocamente ao humanizar o ideal do eu. Por outro lado, o desregramento desses efeitos aparece em razão das exigências crescentes que são impostas ao eu por essa mesma cultura quanto à coerência e ao impulso criador. (Lacan, 1938/2003, p. 79). 
Ao nos debruçarmos sobre o estudo do complexo de Édipo, podemos ter o alcance do quanto há uma especificidade psicológica na relação entre os pais e, entre os pais e a criança. Quanto ao papel do pai, Lacan ressaltou sua dupla função, ou seja, a de autoridade interditora e a de revelação de um caminho sexual possível.

O supereu e o ideal do eu de uma criança são formados não necessariamente conforme o eu dos pais, mas sim pelas intenções que Ihe chegam via afeto. Com isso, Lacan (1938/2003) concluiu que a neurose parental tinha um papel determinante nos sintomas neuróticos de cada sujeito, tal como se pode ver evidenciado na clínica analítica. Portanto, os conflitos e as tensões subjacentes ao complexo de Édipo definem os mecanismos psicológicos e, consequentemente, o destino da neurose. Lacan também afirmou que os conflitos nas relações do filho com o pai traduzem a oposição das gerações e dão testemunho da própria dialética da tradição do tipo patriarcal. Ele acrescentou que os excessos de dominação paterna teriam como efeito um supereu excessivo, o que poderia se tornar ainda mais patogênico caso a esses excessos se somassem a tirania da estrutura matriarcal, que traz a reboque como aliados os ideais religiosos e seus equivalentes sociais.

A forma como o desmame, a intrusão e o complexo de Édipo são vividos vão cartografando o psiquismo de cada sujeito. Esse mecanismo se efetua a partir dos cortes operados na ilusão de completude narcísica que ocorre desde o desmame, passando pela intromissão do outro vivida como estranho e intruso, até a sublimação da sexualidade no complexo de Édipo. Surge, então, para Lacan, o sujeito da cultura na modernidade.

\section{0 que a psicanálise transmite}

Pensar sobre o caráter revolucionário ou reacionário da teoria psicanalítica é, indubitavelmente, mergulhar na pesquisa sobre a transmissão em psicanálise a partir das formulações de Freud e Lacan acima expostas. Sendo assim, retorno à Leguil (2016), que se dedicou a trabalhar esse tema. Ela acredita que não levar essa vertente em consideração cria uma mal-entendido que acaba por atribuir a Freud e, consequentemente, à psicanálise, uma tarja reacionária. Nesse mesmo viés, estão as ideias de Coelho dos Santos (2018) que acredita que os elementos com os quais a psicanálise opera é da ordem da estrutura.

Freud localizou um ponto intransponível no percurso analítico, quer se trate de um homem ou de uma mulher. Desse ponto, Lacan depreendeu o objeto $a$ e, posteriormente, a tábua da sexuação. As pulsões parciais ganharam uma posição de destaque diante da impossibilidade de uma integração total na fase genital do desenvolvimento psíquico da sexualidade, e, como um resto, elas retornavam naquilo que Lacan chamou de gozo.

Coelho dos Santos (2018, agosto) esclareceu esse ponto ao afirmar que, diante do fantasma do Outro a criança responde alguma coisa. E, é essa alguma coisa que porta a assinatura 
daquele sujeito. Desta feita, o desejo não é anônimo, e sim, singular. A autora considera que a resposta que o Outro dá ao "grito" da criança humaniza essa evocação vocal. Essa interpretação seria marcada, de antemão, pelo lugar que a criança ocupa na fantasia do Outro, mesmo antes do seu nascimento. Para Coelho dos Santos (2018), essa noção foi desenvolvida por Freud (1895/1976), e, posteriormente, Lacan (1959-1960/1988) avançou muito nesse sentido ao afirmar que esse enredo coincide com o momento em que a criança está fazendo a travessia do complexo edipiano. Após esse atravessamento, em torno dos 4 anos de idade, o sujeito advirá se apropriando de tudo o que se sucedeu; o que o relançará a outra dimensão. A partir de então, é esse novo sujeito que fala e interpreta o que estivera em jogo. Portanto, Coelho dos Santos esclarece que através da narrativa se dá a transmissão.

Segundo Coelho dos Santos (2018, agosto), Lacan teria retraduzido a teoria da pulsão freudiana, ao afirmar não existir pulsão fora da linguagem. $O$ que significa que, ao se falar em pulsão, inevitavelmente, há um deslocamento do campo da necessidade. Dito de outra forma, já houve a interpretação advinda do Outro. Avançando em sua explicação, Coelho dos Santos nos permite entender que o que resta subtraído dessa operação é o que Lacan nomeou como objeto $a$. E é esse objeto a que a pulsão contornará, produzindo, a partir desse ponto, a questão que a criança endereçará ao Outro: "o que queres de mim?". A resposta a esse questionamento lançará o sujeito no campo simbólico.

Para Coelho dos Santos (2018, agosto), pode-se reconhecer que Freud (1905/1976), de outra maneira, já havia lançado as sementes para essa leitura de Lacan, quando nomeou as fixações parciais. Ela afirma que Freud estaria entendendo esses pontos como um resto de corpo, ou seja, um ponto de não tradução. Em suas palavras: "[...] um fora do lado, porém não foracluído". Ela acredita que esse resto do corpo está aparelhado pelo significante, pois, a seu ver, o não interpretável está referido ao que já foi interpretado". Com isso, seguindo as ideias desenvolvidas por Lacan (1974-1975. Seminário inédito) no seminário "R.S.I.", Coelho dos Santos declara que o objeto $a$ "[...] não é puro real. No seminário R.S.I., Lacan diz que este objeto está entre os três registros. Portanto, ele tem, além do registro do real, um tanto de simbólico e um tanto de imaginário" (Coelho dos Santos, 2018, agosto).

Coelho dos Santos conclui a aula reiterando que a criança é introduzida nesse jogo em posição de objeto. Contudo, existe nesse corpo uma disposição em se ingressar no mundo da linguagem. Após essa introdução não tem mais como haver um corpo puramente material, como se fosse uma coisa, mas sim um corpo humanizado.

Visando caminhar para a conclusão deste trabalho, retornarei à Leguil (2016), que reconhece que cada sujeito porta uma "marca de fábrica" resultante do primeiro encontro da criança com o gênero de um pai, ou de uma mãe. Nesse encontro as representações da virilidade e da feminilidade são transmitidas. Ela afirma que Lacan construiu um saber sobre o sexual onde a questão do ser homem e ser mulher apontava para essa marca de fábrica, que compreende os 
significantes transmitidos através das gerações. Essa marca determina a maneira como cada um responde ao Outro, antes mesmo de se inscrever nas normas de gênero.

Desta feita, a escolha de objeto passa a obedecer a um regime onde "[...] ser homem ou ser mulher passa necessariamente pela relação não anônima de cada um com seu desejo e com seu regime de gozo, em sua absoluta singularidade" (Leguil, 2016, p. 13). Em outras palavras, a escolha de objeto carrega a marca do que é da ordem da relação do sujeito com seu desejo e com seu gozo. Essa fórmula pessoal não é proveniente nem da natureza e nem da cultura; ao contrário, a essência dessa singularidade é feita de significantes, na medida em que os sujeitos estão submetidos ao campo da fala e da linguagem. "Na leitura proposta por Clotilde Leguil, o que é colocado em destaque é a impossibilidade de se abolir a diferença dos sexos e menos ainda o domínio do gozo, mesmo em uma vida sexual considerada muito liberada" (Reis Santos in Leguil, 2016, p. 18).

No entanto, Leguil se pergunta sobre o que teria transformado algo que é da ordem da estrutura no que passou a ser visto como "[...] uma marca violenta vinda do Outro e levando cada um a renunciar o que tem de mais singular?" (Leguil, 2016, p. 26). Seu argumento é que diante das tensões e dos conflitos no que tange às questões relativas às escolhas sexuais, que se exacerbaram apesar da revolução sexual, vários segmentos de pensadores se insurgiram contra os preconceitos que se revelaram no seio das sociedades. Ela destaca a participação de feministas americanas, ressaltando, particularmente, a influência das ideias de Monique Wittig e Judith Butler.

Essas intelectuais, essas universitárias abalam as crenças estabelecidas, perturbam os preconceitos, desconstroem as tradições. A noção de "gender", utilizada por elas para designar o que há de construído na identificação sexuada, é a ferramenta que lhes permite fazer aparecer a fábrica do gênero, ou seja, a ausência de todo gênero natural. Sexo e gênero tornam-se assim, os dois conceitos que se pode fazer operar para desconectar a relação com o gênero de toda referência à natureza. (Leguil, 2016, p. 27).

Leguil reconhece as grandes contribuições que as teorias dos defensores do gênero trouxeram no que se refere aos direitos das mulheres, homossexuais, e todas as demais classificações de gêneros existentes na atualidade. No entanto, ao que diz respeito à psicanálise, discorda dos pontos levantados por eles, tais como: 1 ) de ser normativa, uma vez que reconhece a existência de dois sexos; 2) de ignorar o corpo, já que trabalha no campo das representações; 3 ) de considerar a heterossexualidade como um modo de vida mais normal que a homossexualidade, na medida em que trabalha com o complexo de Édipo e com o recalque da bissexualidade; 4) de seu fundador ser misógino por identificar na ameaça de castração nos homens, e na inveja do pênis nas mulheres, a alavanca que desdobra os destinos da sexualidade de cada sujeito. 
No entanto, apesar das representações - o Édipo, o recalque da bissexualidade, a ameaça de castração e a inveja do pênis - serem referentes da teoria psicanalítica, segundo Leguil, Freud nunca considerou "[...] que o desejo, seja ele qual for, deveria ser normalizado, nem tampouco que a heterossexualidade goze de um privilégio qualquer em relação a homossexualidade" (Leguil, 2016, p. 42). Consequentemente, o método psicanalítico em nada se aproxima de uma normatização da vida sexual, e sim, da especificidade da vida de cada sujeito, seja ele homo ou heterossexual.

Leguil (2016) advoga a favor de Freud argumentando que, ao distinguir o sexo masculino do feminino, o pai da psicanálise não estava sendo retrógrado ou machista. A ideologia que o precedia no século XVIII era o Iluminismo, na qual havia um único sexo reconhecido, o masculino. Cabia ao feminino a versão do que não era o masculino. Sendo assim, Freud rompeu com a ideia de um único sexo, uma vez que a equivalência apagava a sexualidade feminina. Ouvir as mulheres, tropeçar em suas teorizações até encontrar a diferença anatômica entre os sexos com suas consequências psíquicas distintas não teria feito de Freud um reacionário, mas sim, um revolucionário.

Concluo acreditando que o Outro é para todos! O preconceito estaria em alijar de uma leitura psicanalítica o sujeito que pauta a sua orientação sexual na escolha por um objeto do mesmo sexo. Foi justo o inverso que Freud propôs ao postular que a pulsão não tem objeto definido. A leitura crítica que identifica Freud como um machista conservador deixa de levar em conta o sujeito diante das questões relativas ao desejo e à pulsão.

\section{Nota:}

1. Artigo produzido no contexto do Doutorado orientado pela Prof. Dra. Tania Coelho dos Santos no Programa de Pós-graduação em Teoria Psicanalítica (IP/UFRJ). A pesquisa conta com o financiamento da CAPES.

\section{Referências Bibliográficas}

Coelho dos Santos, T. \& Malcher, F. (2018, agosto). História da Psicanálise: a função paterna da modernidade à contemporaneidade. Disciplina do Programa de Pós-Graduação em Teoria Psicanalítica da Universidade Federal do Rio de Janeiro/ Instituto Sephora de Ensino e Pesquisa de Orientação Lacaniana-ISEPOL.

Freud, S. (1976). Projeto para uma psicologia científica. In J. Salomão (Trad.) Edição standard brasileira das obras psicológicas completas de Sigmund Freud (Vol. 1, pp. 333-454). Rio de Janeiro: Imago (Trabalho original publicado em 1895). 
Freud, S. (1976). Três ensaios sobre a teoria da sexualidade. In J. Salomão (Trad.) Edição standard brasileira das obras psicológicas completas de Sigmund Freud (Vol. 7, pp. 117231). Rio de Janeiro: Imago (Trabalho original publicado em 1905).

Freud, S. (1976). Romances Familiares. In J. Salomão (Trad.) Edição standard brasileira das obras psicológicas completas de Sigmund Freud (Vol. 9, pp. 215-222). Rio de Janeiro: Imago (Trabalho original publicado em 1909).

Freud, S. (1976). Um tipo especial de escolha de objeto feita pelos homens (Contribuições à Psicologia do Amor I). In J. Salomão (Trad.) Edição standard brasileira das obras psicológicas completas de Sigmund Freud (Vol. 11, pp. 167-180). Rio de Janeiro: Imago (Trabalho original publicado em 1910).

Freud, S. (1976). Sobre o Narcisismo: uma introdução. In J. Salomão (Trad.) Edição standard brasileira das obras psicológicas completas de Sigmund Freud (Vol. 14, pp. 75-108). Rio de Janeiro: Imago (Trabalho original publicado em 1914).

Freud, S. (1976). Consequências psíquicas da distinção anatômica entre os sexos. In J. Salomão (Trad.) Edição standard brasileira das obras psicológicas completas de Sigmund Freud (Vol. 19, pp. 271-286). Rio de Janeiro: Imago (Trabalho original publicado em 1925).

Freud, S. (1976). Inibições, Sintomas e Angústia. In J. Salomão (Trad.) Edição standard brasileira das obras psicológicas completas de Sigmund Freud (Vol. 20, pp. 79-170). Rio de Janeiro: Imago (Trabalho original publicado em 1926).

Freud, S. (1976). Mal-estar na civilização. In J. Salomão (Trad.) Edição standard brasileira das obras psicológicas completas de Sigmund Freud (Vol. 21, pp. 65-148). Rio de Janeiro: Imago (Trabalho original publicado em 1930).

Freud, S. (1976). Análise Terminável e Interminável. In J. Salomão (Trad.) Edição standard brasileira das obras psicológicas completas de Sigmund Freud (Vol. 23, pp. 223-270). Rio de Janeiro: Imago (Trabalho original publicado em 1937).

Lacan, J. (1985). O seminário, livro 3: as psicoses. Rio de Janeiro: Zahar (Trabalho original publicado em 1955-1956).

Lacan, J. (1988). O seminário, livro 7: a ética da psicanálise. Rio de Janeiro: Zahar (Trabalho original publicado em 1959-1960).

Lacan, J. (1998). A significação do falo. In Escritos. Rio de Janeiro: Zahar, pp. 692-703 (Trabalho original publicado em 1958).

Lacan, J. (2003). Complexos familiares na formação do indivíduo. In Outros Escritos. Rio de Janeiro: Zahar, pp. 29-90 (Trabalho original publicado em 1938).

Lacan, J. (2008). O seminário, livro 20: mais ainda. Rio de Janeiro: Zahar (Trabalho original publicado em 1972-1973).

Lacan, J. (Seminário inédito). "R.S.I". Rio de Janeiro: Zahar (Trabalho original publicado em 19741975). 
Leguil, C. (2016). O ser e o gênero: homem/mulher depois de Lacan. Belo Horizonte: EBP.

Roudinesco, E. (2016). Sigmund Freud na sua época e em nosso tempo. Rio de Janeiro: Jorge Zahar.

Citacão/Citation: Infante Vieira, M. (mai. 2019 a out. 2019). Transmissão em psicanálise. Revista aSEPHallus de Orientação Lacaniana, 14(28), 73-90. Disponível em www.isepol.com/asephallus. Doi: 10.17852/1809-709x.2019v14n28p73-90

Editor do artigo: Tania Coelho dos Santos.

Recebido/Received: 02/08/2019 / 08/02/2019.

Aceito/Accepted: 04/10/2019 / 10/04/2019.

Copyright: (c) 2019 Associação Núcleo Sephora de Pesquisa sobre o moderno e o contemporâneo. Este é um artigo de livre acesso, que permite uso irrestrito, distribuição e reprodução em qualquer meio, desde que o autor e a fonte sejam citados/This is an open-access article, which permites unrestricted use, distribution, and reproduction in any medium, provided the author and source are credited. 